\title{
Misleading appearance in cervical lymph node US diagnosis - a report on sarcoidosis, Warthin tumor and squamous cell carcinoma metastases
}

\author{
Irina Sandu1, Manuela Lenghel², Grigore Băciuț³, Cristian Dinu, Carolina Botar-Jid², Dan \\ Vasilescu $^{2}$, Sorin M. Dudea ${ }^{2}$
}

${ }^{1}$ Clinical Rehabilitation Hospital Radiology Department, ${ }^{2}$ Emergency Clinical County Hospital, Radiology Department, ${ }^{3}$ Cranio-Maxillo-Facial Surgery Department, "Iuliu Haţieganu" University of Medicine and Pharmacy, ClujNapoca, Romania

\begin{abstract}
Ultrasonography, with its various techniques (grey-scale, color Doppler, sonoelastography) offers many signs for the differentiation between benign and malignant neck lymph nodes. In spite of recent progress, the US appearance may be misleading. We present three cases in which the ultrasonographic appearance of the lymph nodes was misleading as compared to the final diagnosis established by histopathology.
\end{abstract}

Keywords: ultrasonography, lymph nodes, neck

\section{Introduction}

Different types of disease such as infection, inflammation, primary or secondary malignant tumors may involve the lymph nodes of the neck. The differentiation between benign and malignant lymph nodes is the most important practical issue when assessing neck lymphadenopathy by means of imaging.

Ultrasonography (US) is the first imaging technique used in the evaluation of the cervical lymphadenopathy, due to its resolution for superficial structures. The main advantages of US are the lack of irradiation, the noninvasiveness and the fact that it can be repeated as often as necessary. Grey-scale, color and pulsed Doppler and, more recent, elastographic criteria are used for differentiating benign from malignant lymph nodes [1-3].

Received 20.03.2014 Accepted 06.04.2014

Med Ultrason

2014, Vol. 16, No 2, 182-185

Corresponding author: Lavinia Manuela Lenghel

Radiology Department,

"Iuliu Haţieganu" University of Medicine and Pharmacy

1-3 Clinicilor str,

400006, Cluj-Napoca, Romania

E-mail:manu_2416@yahoo.com
As evocative as US findings may be, prudent reporting of US findings is advisable, as less frequent disease may produce misleading appearance. This paper reports three cases where the evocative US appearance was contradicted by histopathology.

\section{Case 1}

A 63 year old man was admitted in the Cranio-MaxilloFacial surgery department for the presence of a tumor on the right side of the floor of the mouth that, on the clinical examination, had a malignant appearance with ulcerations and associated submental stiff area suspected to represent lymphadenopathy. The patient was referred to US examination with the suspicion of a necrotic metastatic submental lymph node. US revealed diffuse edema of the soft tissues but no fluid collection and no lymph nodes in the submental region. However, in the IIIrd level (middle jugular group) multiple hypoechoic rounded cervical lymph nodes, up to $15 \mathrm{~mm}$ in diameter, with mixed pattern of vascularization, (central and peripheral) were found. Elastography identified large blue areas (stiffness), on more than $50 \%$ of the lymph node (fig 1). The appearance was reported as highly suspicious for malignancy, probably metastases. Surgical histology showed granulomatous inflammation of lymph nodes, compatible with sarcoidosis, 

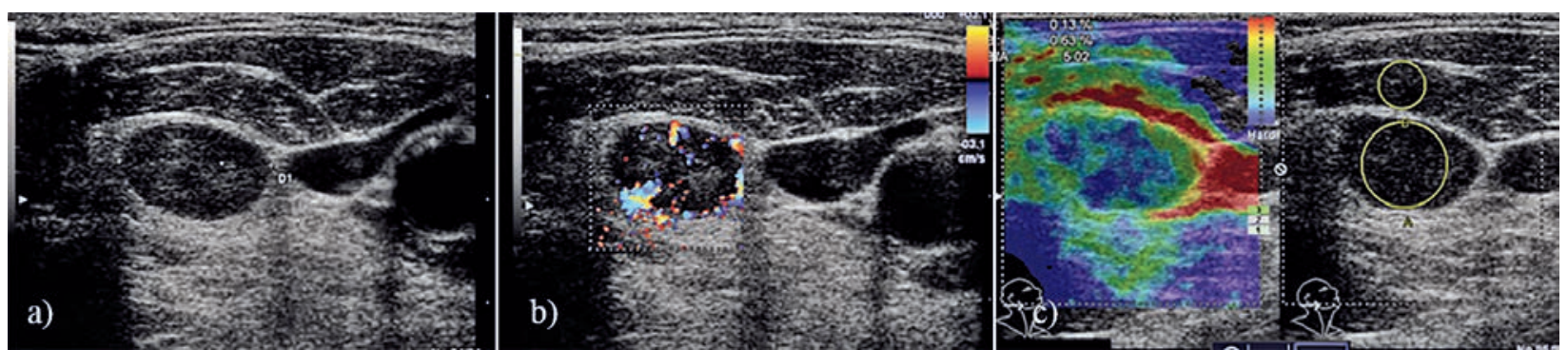

Fig 1. Appearance of one of the IIIrd level lymph nodes: round, well-defined, hypoechoic, homogeneous (a). Color Doppler of the lymph node showing a mixed pattern of vascularization (b). Sonoelastography of the lymph node displaying predominant stiff texture (c).

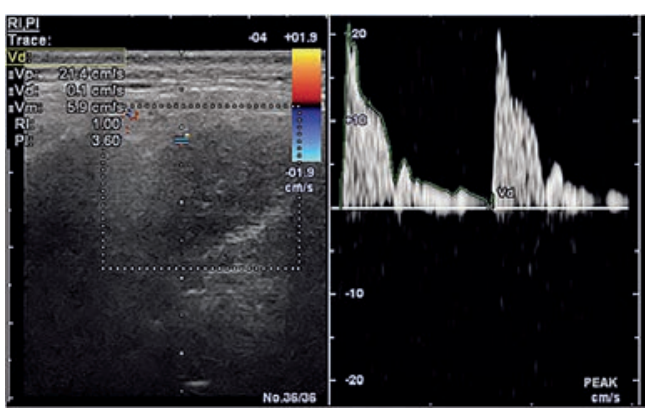

Fig 2. Color and Pulsed wave Doppler appearance of the mass (heterogeneous structure, predominant hypoechoic, with ill-defined margins) showing vessels with high impedance value.

with no malignant cells. The excisional specimen of the mouth' tumor excluded also the malignancy: erosions and ulceration of the oral mucosa, acanthotic squamous epithelium, lymphocytic infiltrate in the corium and fibrosis. Further investigations were recommended to exclude other granulomatous disease, tuberculosis in particular. The patient was directed to the pneumo-phthisiology department for chest investigations, but no follow-up was available.

\section{Case 2}

A 74 year old man, with previous left sided parotid surgery for a Warthin tumor one year before presenta- tion, was admitted to the surgery department for a painful tumor in the same left side parotido-masseteric region. In the same hospitalization a solid type basal cellcarcinoma of the left nasal planum was diagnosed. He was referred for US. The US examination revealed an oval (27/20/18 $\mathrm{mm}$ ) hypoechoic lesion in the deeper part of the left parotidian lodge, with ill-defined margins and heterogeneous structure. The Doppler study showed few vascular pedicles, both central and peripheral, with high impedance value (fig 2). On sonoelastography, the mass had a predominantly stiff appearance raising the suspicion for malignancy. Lymph nodes were present in both parotid glands, but no US suspicion for malignancy was found. Histopathological examination after surgical removal of the macronodular structure showed papillary cystadenoma lymphomatosum (Warthin tumor).

\section{Case 3}

A 45 year old man presented with the clinical diagnosis of left laterocervical cyst (painless, mobile, soft tumor discovered by the patient one year before). The US examination showed on the Ist B level (submandibular group) an oval large (45/44/28 $\mathrm{mm}$ ) hypoechoic mass with reticulation. On color Doppler US the vascular pattern was chaotic, with both peripheral and central vessels with low impedance value. Elastographic examination found blue areas (hard areas) in more than $50 \%$ of the lymph node
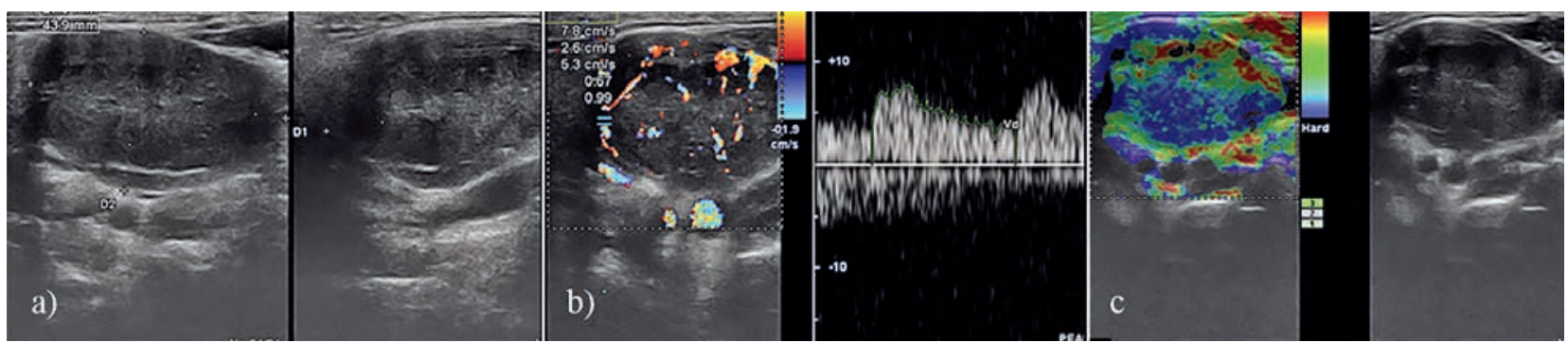

Fig 3. Two orthogonal views of the mass showing a hypoechoic appearance and reticulation (a). Color and Pulsed wave Doppler reveal a chaotic vascular pattern with both central and peripheral vessels, with low impedance value (b). Sonoelastography of the mass showing a predominant stiff texture (c). 
(fig 3). Other cervical lymph nodes were found on the IIIrd and IVth level (lower jugular group) on the left side, with similar characteristics, but smaller (long axis 13 $\mathrm{mm})$. On the right side the lymph nodes were small with typical reactive appearance. Surgical histology revealed the aspect of metastases from squamous cell carcinoma. The patient was referred to the oncology department.

\section{Discussions}

US is the first imaging modality used in the evaluation of cervical lymphadenopathy, due to its high resolution for superficial structures and the many options this technique offers: grey scale, color and power Doppler and recently elastography and contrast enhancement [1-4].

The differentiation between benign and malignant cervical lymphadenopathy can be difficult when typical features of both are present. Reactive inflammatory lymph nodes are small with oval shape, well defined margins, hyperechoic hilum and central vascular pattern with low impedance. The characteristics of malignant lymph nodes, most often metastatic, are: large hypoechoic nodes with round shape, no hyperechoic hilum, ill-defined margins and peripheral vascular pattern with high impedance. Lymphomatous nodespresent a peculiar appearance: multiple large rounded lymph nodes with matting, intranodal reticulation and mixed vascular pattern, both central and peripheral with variable impedance $[1,5,6]$.

When these features interfere, the US diagnosis becomes a challenge. The history of the patient and the clinical examination are tools that have to be used in every step of the diagnosis. Nevertheless, the lymph nodes appearance can be misleading and the final diagnosis remains the histopathological diagnosis.

In the first case, the patient was referred for the evaluation of a suspectedsubmentallymh node, presumably necrotic, given the appearance of the oral tumor. US depicted no significant changes in the suspected area, but it revealed lymph nodes on the IIIrd level [7]. The number of the lesions, their rounded shape, and the hypoechoicaspect on greyscale US raised the suspicion of metastases, given the clinical presentation. The elastographic appearance with large stiff areas in more than $50 \%$ of the lymph node, a pattern 5 [8] further indicated malignancy.However, the histopathological result was of granulomatous inflammation compatible with sarcoidosis. The outcomewas unexpected as the vascular patternseen on Doppler US also suggested malignancy (metastasis or lymphoma) [1]. It is known that the hypoechoic center or the internal echoes could be found in $77 \%$ and $84 \%$ of tuberculous lymph nodes [5], but, to the best of our knowledge, there are no published descriptions regarding the sonographic appearance of cervical lymph nodes affected by sarcoidosis, as suggested by the pathology in this case. A recent study [9] found that the heterogeneous echotexture and the presence of coagulation necrosis are fairly specific for tuberculosis, when compared with sarcoidosis, on endobronchial US. However, a definite diagnosis of sarcoidosis implies clinical examination, radiologic, laboratory and histologic findings and when cervical lymph nodes are the only site involved, followup is needed $[10,11]$.

In the second case, the clinical presentation was misleading. The patient was admitted for a provennasal planummalignancy and the evaluation of cervical lymph nodes in search of metastases was undertaken. Greyscale US revealed aheterogeneous hypoechoiclarge mass inside the left parotid gland. Since the patient had been operated on the same side for a Warthin tumor, a recurrent Warthin tumor at one year interval was not suspected and the mass was considered undetermined. However, the suspicion of malignancy could not be discarded as the solid heterogeneous mass showed cystic areas within the lesion associated with reduced vascularization with high-impedance - all being signs of malignancy $[1,6]$. Metastases from basal cell carcinoma are veryrare [12], one of the sites being the lymph nodes inside the parotid gland [13]. Surprisingly, the lesion proved to be a Warthin tumor. The adenolymphoma orWarthin tumoris a benign intraparotidiantumor,more frequently located in the superficial part of the gland, with deep location, as in our case, being of rare occurrence [14]. These tumors are well-defined oval lesions withheterogeneous structure due to hypo-anechoic areas of variable size. The cystic components are highly suggestive for the diagnosis [15]. Commonly, the Warthin tumor has a very slow growth. The discovery of a rather large tumor brings on the hypothesis of a multifocal tumor, overlookedat the previous clinical and imaging examination performed in an outer institution, one year before. The Warthin tumor is the most common multifocal parotid tumor $[14,16]$.

In the last case, the clinical suspicionwas of a laterocervical cyst. US revealed a large, hypoechoiclymph node, with intranodal reticulation and mixed vascular pattern,associated with predominant stiff appearance at sonoelastography classified as pattern 5 [8]. Sonography indicated malignancy, raising the possibility of lymphoma $[6,8,17]$ due to the large number of involved nodes, its hypoecogenity, reticulation andno other known malignancy. The histopathological diagnosis of metastases from squamous cell carcinomawas unexpected considering thelong evolution of the lump and the lack of clinical history. 
These cases show that, in spite of progress in the assessment of neck lymph nodes with US and the use of new techniques such as elastography, it is still risky to formulate a diagnosis of histopathological value, based solely on the US appearance. Further developments such as contrast enhanced ultrasonography might increase the diagnosis accuracy $[4,18]$. The clue to an accurate diagnosis relies in the corroboration of clinical data with US and other imaging information, having in mind that confrontation with pathology is always necessary.

\section{References}

1. Gupta A, Rahman K, Shaid M, et al. Sonographic assessment of cervical lymphadenopathy: role of a high-resolution and color Doppler imaging. Head Neck 2011; 33: 297 302.

2. Ahuja AT, Ying M. Sonographic evaluation of cervical lymph nodes. AJR Am J Roentgenol 2005; 184: 1691-1699.

3. Das D, Gupta M, Kaur H, Kalucha A. Elastography: the next step. J Oral Sci 2011; 53: 137-141.

4. Zenk J, Bozzato A, Steinhart H, Greess H, Iro H. Metastatic and inflammatory cervical lymph nodes as analyzed by contrast-enhanced color-coded Doppler ultrasonography: quantitative dynamic perfusion patterns and histopathologic correlation. Ann Otol Rhinol Laryngol 2005; 114: 43-47.

5. Khanna R, Sharma AD, Khanna S, Kumar M, Shukla RC. Usefulness of ultrasonography for the evaluation of cervical lymphadenopathy. World J Surg Oncol 2011; 9: 29.

6. Dudea SM, Lenghel M, Botar-Jid C, Vasilescu D, Duma M. Ultrasonography of superficial lymph nodes: benign vs. malignant. Med Ultrason 2012; 14: 294-306.

7. Lenghel LM, Baciut G, Botar-Jid C, Vasilescu D, Bojan A, Dudea SM. Ultrasonographic identification of the anatomical landmarks that define cervical lymph nodes. Med Ultrason 2013 ; 15 : 29-34.
8. Lenghel LM, Bolboacă SD, Botar-Jid C, Băciuț G, Dudea $\mathrm{SM}$. The value of a new score for sonoelastographic differentiation between benign and malignant cervical lymph nodes. Med Ultrason 2012; 14: 271-277.

9. Dhooria S, Agarwal R, Aggarwal AN, Bal A, Gupta N, Gupta D. Differentiating tuberculosis from sarcoidosis by sonographic characteristic of lymph nodes on endobronchial ultrasonography. A study of 165 patients. J Thorac Cardiovasc Surg 2014 Jan 27, doi: 10.1016/j.jtcvs.2014.01.028.

10. Chen HC, Kang BH, Lai CT, Lin YS. Sarcoidal granuloma in cervical lymph nodes. J Chin Med Assoc 2005; 68: 339342.

11. Kwon YS, Jung HI, Kim HJ, et al. Isolated cervical lymph node sarcoidosis presenting in an asymptomatic neck mass: a case report. Tuberc Respir Dis (Seoul) 2013; 75: 116-119.

12. Von Domarus H, Stevens PJ. Metastatic basal cell carcinoma. Report of five cases and review of 170 cases in the literature. J Am Acad Dermatol 1984; 10: 1043-1060.

13. Kurian RR, Di Palma S, Barett AW. Basal cell carcinoma metastatic to parotid gland. Head Neck Pathol 2013 Nov 15, doi: 10.1007/s12105-013-0507-3.

14. Thangarajah T, Reddy VM, Castellanos-Arango F, Panarese A. Current controversies in the management of Warthin tumour. Postgrad Med J 2009; 85: 3-8.

15. The Neck. In: Catalano O, Nunziata A, Siani A (eds). Fundamentals in Oncologic Ultrasound. Milan, Springer 2009: 113-144.

16. Hancock BD. The influence of multicentricity in the treatment of Warthin's tumour: the Manchester expeience. In: McGurk M, Renehan A, eds. Controversies in the management of salivary gland disease. Oxford: Oxford University Press, 2001: 117-22.

17. Ahuja AT, Ying M, Ho SY, Antonio G, Lee YP, Wong KT. Ultrasound of malignant cervical lymph nodes. Cancer Imaging 2008; 8: 48-56.

18. Fodor D, Pascu I, Pop S, Poanta L. The utility of elastography and CEUS for the differentiation between benign and malignant cervical lymphadenopathy. Three cases report. Med Ultrason 2013; 15: 63-66. 